Original Article

\title{
Impact of Orthodontic Treatment Complexity on Oral Health-Related Quality of Life in Turkish Patients: A Prospective Clinical Study
}

Hatice Kübra Olkun' (D), Gülşilay Sayar² (D)

'Department of Orthodontics, Okan University School of Dentistry, İstanbul, Turkey

${ }^{2}$ Department of Orthodontics, Istanbul Medipol University School of Dentistry, Istanbul, Turkey

Cite this article as: Olkun HK, Sayar G. Impact of Orthodontic Treatment Complexity on Oral Health-Related Quality of Life in Turkish Patients: A Prospective Clinical Study. Turk J Orthod 2019; 32(3): 125-31.

\section{ABSTRACT}

Objective: The study aimed to evaluate the relationship between orthodontic treatment complexity and oral health-related quality of life (OHRQoL) and to assess the impact of malocclusion and orthodontic treatment on OHRQoL in orthodontic patients with regard to gender and age.

Methods: This prospective clinical study included 102 patients aged 13-35 years who were referred to the orthodontic department. The impact of orthodontic treatment complexity was assessed using the Index of Complexity, Outcome and Need (ICON). The Turkish version of the Oral Health Impact Profile (OHIP-14) was used to examine the subjects for OHRQoL before and after treatment. The before and after treatment data ( $\mathrm{T} 1$ and $\mathrm{T} 2$, respectively) were tested using a paired t-test, and one-way analysis of variance (ANOVA) with the Bonferroni test was used to assess the differences in OHIP-14 across groups, as defined by the ICON. The cross-sectional comparisons between genders and age groups before and after treatment were tested using the Student's t-test. The level of significance was set to a p value of 0.05 .

Results: Patients with moderate treatment complexity reported a significantly negative impact on the psychological disability domain compared to the difficult treatment complexity. OHRQOL improved after treatment. Females showed statistically significant and highest scores on the physical pain domain compared to males. Adults showed a statistically significant negative impact on the psychological domains before treatment as well as a statistically significant positive impact on the psychological disability domain after treatment compared to adolescents $(p<0.05)$.

Conclusion: Orthodontic treatment improves OHRQoL, and orthodontic treatment complexity does not seem to have an impact on OHRQoL.

Keywords: Oral health-related quality of life, treatment complexity, ICON, OHIP-14, orthodontic treatment, malocclusion

\section{INTRODUCTION}

Oral Health-Related Quality of Life (OHRQoL) is defined as "a multi-dimensional construct that reflects people's comfort when eating, sleeping, and social interaction; their self-esteem; and their satisfaction with respect to their oral health" (1). A variety of OHRQoL instruments have been developed (2), of which multiple-item questionnaires are the most widely used methods to evaluate the functional and psychosocial impacts of oral diseases (3). Several instruments that have been thoroughly tested to assess their psychometric properties, such as reliability, validity, and responsiveness, are widely used for measuring oral health (4).

Currently, the Oral Health Impact Profile (OHIP) is the most comprehensive and widely used instrument to measure OHRQoL. It was developed by Slade in 1994 and has been validated in cross-sectional population studies of the elderly (5). 
The Index of Complexity, Outcome, and Need (ICON) has been used in literature to evaluate orthodontic treatment need, complexity, and outcome. Although the term treatment complexity is a separate parameter from the malocclusion severity, both measure the same latent trait; hence, they are related to each other (6). Many researchers have found that complex cases are more severe and require more effort associated with more extraction, treatment plan changes, more appointments, longer treatment duration, and cooperation problems $(7,8)$. Patients with complex treatment or severe malocclusion may report various oral health impacts that affect their well-being in many ways. Previous research findings indicate that the perception of malocclusion varies across specialists and patients and that the severity of malocclusion does not always reflect $\operatorname{OHRQoL}(9,10)$.

The impact of malocclusion differs between genders and age groups. Most of the studies have indicated that females experience poorer $\mathrm{OHRQOL}$ than males. This gender difference in malocclusion perception could be because females pay more attention to their appearance and therefore refer to orthodontic clinics more often than males. There has been an increasing demand for orthodontic treatment by adults, and the key motivations for them are mostly the social and psychological effects of orthodontic treatment. Previous researches have revealed that the relation between gender, age, and the satisfaction of dental appearance is still controversial (11-16).

It is hypothesized that malocclusion and orthodontic treatment would not have an adverse effect on the oral health status and a negative impact on the quality of life as a whole. Although there have been studies on the impact of orthodontic treatment need on OHRQoL, to the authors' knowledge, there is no published research using ICON and OHIP-14 on Turkish patients and studying no treatment need but treatment complexity. This has encouraged us to carry out this study to obtain the baseline information for Turkey. Therefore, this study was conducted to assess (a) the impact of malocclusion and orthodontic treatment on OHRQoL with regard to gender and age and (b) the impact of orthodontic treatment complexity on OHRQoL.

\section{METHODS}

The present prospective research study was approved by the ethics research committee of Medipol University. The participants or where appropriate their parents were informed about the purpose and procedure of the study, and written informed consent was obtained.

\section{Participants}

A total of 102 ( 65 females and 37 males) patients were included in this study. All participants selected from patients who had undergone orthodontic treatment for the period 2013-2016 at the Department of Orthodontics, Medipol University Hospital were assessed. The overall response rate was $100 \%$. Table 1 shows the demographic characteristics and ICON complexity scores. The mean age of all participants was $19.6 \pm 5.1$ years (range: 13-35), they were stratified into two age groups: $55.9 \%$ were adolescents (range: $13-17$ years) and $44.1 \%$ were adults (range: 18-35 years).

\section{Inclusion Criteria}

The inclusion criteria were as follows: (1) 13-35 years of age (2) planned for comprehensive fixed orthodontic treatment; (3) no missing teeth with the exception of third molars; (4) no dental caries or periodontal problems; (5) no craniofacial anomalies or chronic medical problems; and (6) no previous orthodontic treatment of any type.

\section{Interview and Questionnaire}

All recruited patients were subjected to a face-to-face interview. They were asked to provide information concerning their demographic data, including age, gender, and medical status; they were also questioned whether they had previously received any type of orthodontic treatment. In addition, they were required to complete the shortened version of the OHIP-14 instrument to measure the OHRQoL.

The OHIP-14 questionnaire, which has been validated in Turkey (17) and has shown good psychometric properties, was used to assess OHRQoL. The OHIP questionnaire evaluated dysfunction, discomfort, and disability caused by oral disorders. Basically, the original OHIP is a 49-item measure, with statements divided into seven dimensions, namely functional limitation, pain, psychological discomfort, physical disability, psychological disability, social disability, and handicap.

The OHIP-14 is a self-administered, short-version of the original questionnaire and includes 14 questions with seven domains that are used to measure the impact of orthodontic treatment on OHRQoL. The domains are functional limitation (Q1 and Q2), physical pain (Q3 and Q4), psychological discomfort (Q5 and Q6), physical disability (Q7 and Q8), psychological disability (Q9 and Q10), social disability (Q11 and Q12), and handicap (Q13 and Q14). Subjects were asked how they had experienced negative impacts in these dimensions, and their responses to the items were recorded using a five-point Likert scale $(0=$ never, $1=$ hardly ever, $2=$ occasionally, $3=$ fairly often, $4=$ very often). The total OHIP score was computed by adding the ratings of all questionnaire items (additive count method). The total OHIP-14 score ranged from 0 to 56 , and the domain scores ranged from 0 to 8 . This questionnaire was administered before bonding (T1) and after

\section{Table 1. Demographic characteristics and ICON}

\begin{tabular}{|lcc|} 
Variable & $\mathbf{n}$ & $\%$ \\
\hline Gender & & \\
Female & 65 & 63.7 \\
Male & 37 & 36.3 \\
Age, years & & \\
$13-17$ & 57 & 55.9 \\
$18-35$ & 45 & 44.1 \\
ICON complexity scores & & \\
Easy & 11 & 10.8 \\
Mild & 38 & 37.3 \\
Moderate & 15 & 14.7 \\
Difficult & 12 & 11.8 \\
Very difficult & 26 & 25.5 \\
\hline
\end{tabular}


de-bonding (T2). The OHIP-14 scores were calculated using the mean values. Higher OHIP-14 scores indicated poorer OHRQoL.

Each patient was examined for orthodontic treatment complexity using the ICON before starting fixed orthodontic treatment. The ICON was developed by Daniels and Richmond (18) in 2000 as an international index based on the consensus of 97 specialist orthodontists from 9 countries, including America and 8 European countries. This index consists of 5 components: (1) Aesthetic Component of Index of Orthodontic Treatment Need, (2) Upper arch crowding/spacing, (3) Cross-bite, (4) Incisor open-bite/overbite, and (5) Buccal segment anterior-posterior relation of Peer Assessment Rating. Each component has a weight coefficient and these components are scored according to the ICON proto-

\section{Table 2. Gender and age distribution by groups}

\begin{tabular}{|lccccc|}
\hline & Very Difficult & Difficult & Moderate & Mild & \\
\hline Easy Gender & & & & & \\
Female & 11 & 4 & 13 & 27 & 6 \\
Male & 15 & & 2 & 11 & 5 \\
Age, years & & 8 & 6 & 18 & 7 \\
$13-17$ & 18 & 4 & 9 & 20 & 4 \\
$18-35$ & 8 & & & & \\
\hline
\end{tabular}

col; the sum was then calculated to obtain a total score. The total score was evaluated as easy if it was $<29$, as mild if between 29 and 50, as moderate if between 51 and 63, as difficult if between 64 and 77, and as very difficult if greater than 77. According to the ICON, a vast majority of subjects were mild followed by very difficult group; however, the least was the easy group.

\section{Method Error}

Both OHIP-14 and ICON assessment was performed by only one investigator (H.K.O.) who was trained to use the ICON. The reliability and validity were assessed by examining internal consistency and reproducibility. The kappa value was used to measure inter-item and itemscore correlations by repeating the administration of the OHIP to $10(10 \%)$ of the subjects after 2 weeks (test-retest correlation). The kappa values of the re-examined questionnaire were 0.86 for OHIP-14 and 0.99 for ICON. As a very strong correlation and insignificant differences were noted, it was assumed that the results would be reliable.

\section{Statistical Analysis}

The Statistical Package for Social Sciences software version 18.0 (IBM Corp.; Armonk, NY, USA) was used to perform the statistical analysis. According to Shapiro Wilk-W test, data distributed normal. The mean differences between before- and after-treatment data (T1 and T2, respectively) were tested using a paired t-test.

Table 3. OHIP-14 overall scores and domain scores among treatment complexity groups before treatment (T1) and after treatment (T2)

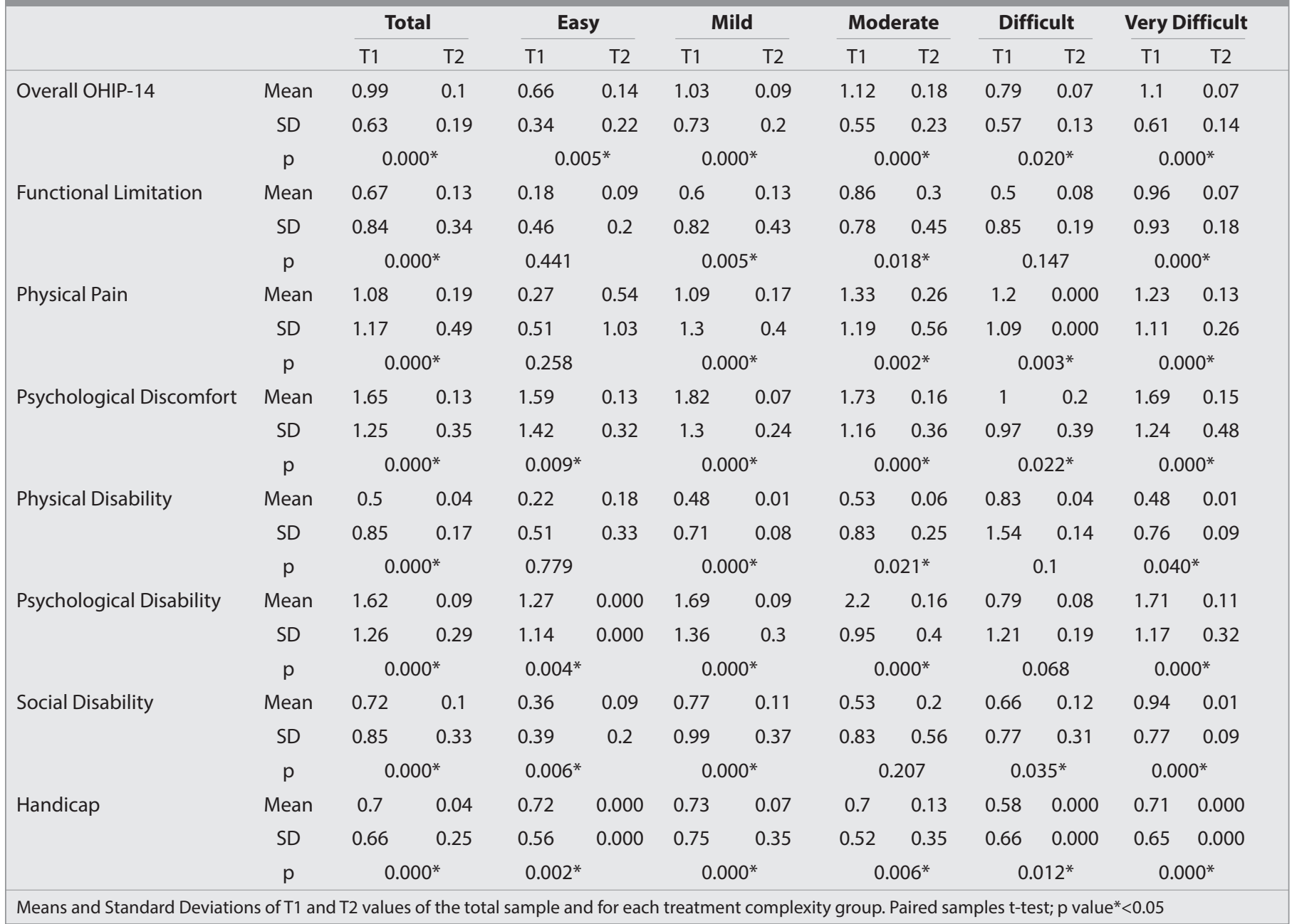


The mean differences between ICON groups (complexity) were tested using the one-way analysis of variance (ANOVA) with the Bonferroni test as a post-hoc. The cross-sectional comparisons between gender groups and age groups before and after treatment were performed using Student's t-test. The level of significance was set at a $p$ value of 0.05 .

\section{RESULTS}

Table 2 shows the gender and age distribution according to treatment complexity groups. In the moderate group, a vast majority of subjects were females (86\%).

Table 3 shows the mean scores in the overall and domain items of OHIP-14 among treatment complexity groups before (T1) and after treatment (T2). The mean overall score for OHIP-14 for T1 was significantly higher compared to T2 (0.99 and 0.1 , respectively, $p<0.05)$. The psychological discomfort domain had the highest reported impact with a mean score of 1.65 , whereas the mean score of the physical disability domain was 0.5 of the OHIP-14, indicating the lowest impact due to malocclusion in patients. The paired sample t-test analysis showed that OHRQoL improved for $\mathrm{T} 2$ regardless of the type of treatment complexity. Table 4 shows the OHIP-14 domain scores among treatment complexity groups before treatment. The one-way ANOVA and Bonferroni test were used to compare results between groups defined by the ICON. A significant difference in the psychological disability domain was obvious with respect to orthodontic treatment complexity $(p<0.05)$. Participants with moderate treatment complexity reported a significantly negative impact on the

Table 4. OHIP-14 domain scores among treatment complexity groups before treatment (T1)

\begin{tabular}{|c|c|c|c|c|c|c|c|}
\hline & $\begin{array}{c}\text { Easy (a) } \\
\text { T1 Mean } \pm S D\end{array}$ & $\begin{array}{c}\text { Mild (b) } \\
\text { T1 Mean } \pm \text { SD }\end{array}$ & $\begin{array}{l}\text { Moderate (c) } \\
\text { T1 Mean } \pm \text { SD }\end{array}$ & $\begin{array}{l}\text { Difficult (d) } \\
\text { T1 Mean } \pm \text { SD }\end{array}$ & $\begin{array}{l}\text { Very Difficult (e) } \\
\text { T1 Mean } \pm S D\end{array}$ & $\begin{array}{c}\text { ANOVA } \\
\mathbf{p}\end{array}$ & $\begin{array}{c}\text { Bonferroni } \\
\mathbf{p}\end{array}$ \\
\hline Functional Limitation & $0.18 \pm 0.46$ & $0.60 \pm 0.82$ & $0.86 \pm 0.78$ & $0.50 \pm 0.85$ & $0.96 \pm 0.93$ & 0.077 & \\
\hline Physical Pain & $0.27 \pm 0.51$ & $1.09 \pm 1.30$ & $1.33 \pm 1.19$ & $1.20 \pm 1.09$ & $1.23 \pm 1.11$ & 0.166 & \\
\hline Psychological Discomfort & $1.59 \pm 1.42$ & $1.82 \pm 1.30$ & $1.73 \pm 1.16$ & $1 \pm 0.97$ & $1.69 \pm 1.24$ & 0.395 & \\
\hline Physical Disability & $0.22 \pm 0.51$ & $0.48 \pm 0.71$ & $0.53 \pm 0.83$ & $0.83 \pm 1.54$ & $0.48 \pm 0.76$ & 0.571 & \\
\hline Psychological Disability & $1.27 \pm 1.14$ & $1.69 \pm 1.36$ & $2.20 \pm 0.95$ & $0.79 \pm 1.21$ & $1.71 \pm 1.17$ & $0.048^{*}$ & $0.038^{*} \mathrm{c}>\mathrm{d}$ \\
\hline Handicap & $0.72 \pm 0.56$ & $0.73 \pm 0.75$ & $0.70 \pm 0.52$ & $0.58 \pm 0.66$ & $0.71 \pm 0.65$ & 0.974 & \\
\hline
\end{tabular}

Table 5. OHIP-14 overall scores and domain scores among gender groups, cross-sectional comparisons for before treatment (T1) and after treatment (T2)

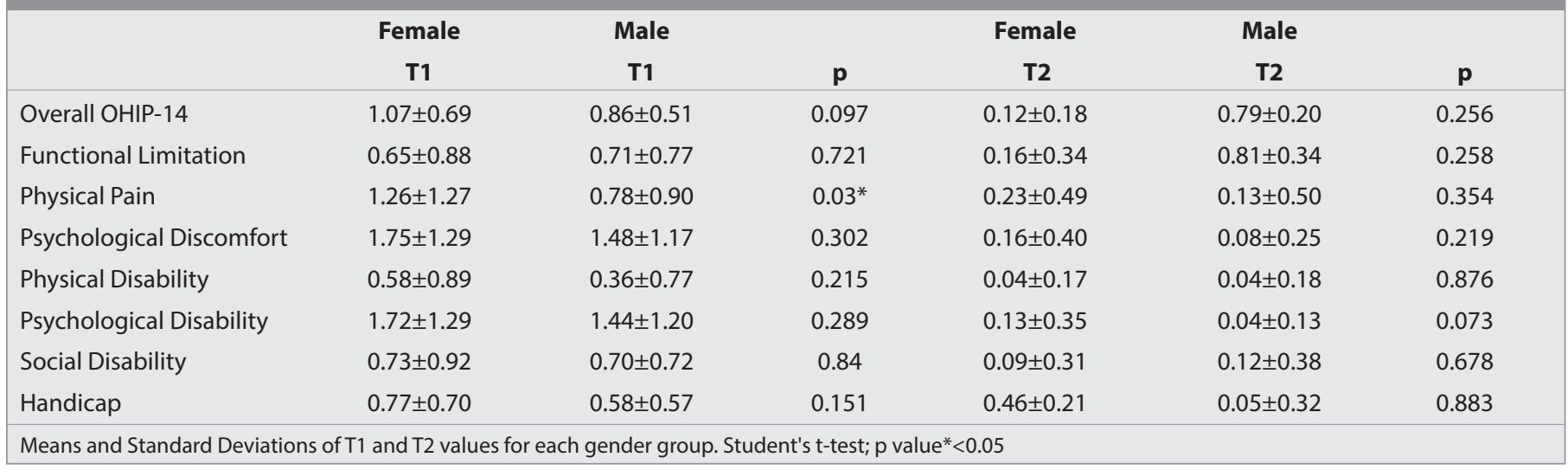

Table 6. OHIP-14 overall scores and domain scores among age groups, cross-sectional comparisons for before treatment (T1) and after treatment (T2)

\begin{tabular}{|lcccccc|} 
& $\mathbf{1 3 - 1 7}$ & $\mathbf{1 8 - 3 5}$ & & $\mathbf{1 3 - 1 7}$ & $\mathbf{1 8 - 3 5}$ \\
Age & $\mathbf{T 1}$ & $\mathbf{T 1}$ & $\mathbf{p}$ & $\mathbf{T 2}$ & $\mathbf{T}$ & $\mathbf{T}$ \\
Overall OHIP-14 & $0.92 \pm 0.65$ & $1.08 \pm 0.60$ & 0.206 & $0.13 \pm 0.22$ & $0.07 \pm 0.12$ & 0.098 \\
Functional Limitation & $0.66 \pm 0.82$ & $0.68 \pm 0.87$ & 0.896 & $0.14 \pm 0.36$ & $0.12 \pm 0.32$ & 0.793 \\
Physical Pain & $1.15 \pm 1.16$ & $1.00 \pm 1.18$ & 0.503 & $0.17 \pm 0.52$ & $0.22 \pm 0.47$ \\
Psychological Discomfort & $1.41 \pm 1.13$ & $1.96 \pm 1.34$ & $0.026^{*}$ & $0.18 \pm 0.40$ & $0.06 \pm 0.27$ & 0.086 \\
Physical Disability & $0.51 \pm 0.77$ & $0.48 \pm 0.96$ & 0.868 & $0.70 \pm 0.22$ & $0.001 \pm 0.07$ & 0.063 \\
Psychological Disability & $1.37 \pm 1.17$ & $1.93 \pm 1.31$ & $0.027^{*}$ & $0.14 \pm 0.37$ & $0.03 \pm 0.12$ & $0.034^{*}$ \\
Social Disability & $0.73 \pm 0.83$ & $0.71 \pm 0.88$ & 0.881 & $0.14 \pm 0.42$ & $0.04 \pm 0.17$ \\
Handicap & $0.61 \pm 0.69$ & $0.82 \pm 0.60$ & 0.115 & $0.07 \pm 0.31$ & 0.095 \\
\hline Means and Standard Deviations of T1 and T2 values for each age group. Student's t-test; $p$ value* $<0.05$ & & $0.02 \pm 0.14$ \\
\hline
\end{tabular}


psychological disability domain compared to difficult treatment complexity $(p<0.05)$.

Table 5 shows OHIP-14 overall and domain scores among gender groups and cross-sectional comparisons of T1 and T2. Females showed a statistically significant negative impact on the physical pain domain compared to males for T1 $(p<0.05)$.

Table 6 shows the OHIP-14 overall and domain scores among age groups and cross-sectional comparisons for T1 and T2. Adults showed a statistically significant negative impact on the psychological discomfort and psychological disability domains compared to adolescents for T1 and showed a statistically significant positive impact on the psychological disability domain for T2 $(p<0.05)$.

\section{DISCUSSION}

The present study aimed to evaluate the impact of orthodontic treatment with regard to gender and age, as it is challenging to understand the impact of orthodontic treatment complexity without understanding the independent effect of malocclusion severity and vice versa. To evaluate the effect of orthodontic treatment on oral health, the subjects were stratified according to two age groups and gender. The incorporation of these multi-variables against the responses of subjects to the questionnaire used to evaluate their oral health status renders a more comprehensive study.

Many studies have been conducted on the effect of malocclusion and orthodontic treatment on the QoL $(12,14-16)$. In our study, the effect of malocclusion on the QoL was measured using the OHIP-14 questionnaire. Although OHIP-14 is a widely used questionnaire, cultural differences might have an impact on the results. Therefore, the second aim was to produce baseline records for Turkish patients and to compare the results with other ethnicitybased studies. Similar to other studies, the results of the present investigation showed that malocclusion has a negative effect on the QoL of individuals (12, 19-25). However, the patient groups, questionnaires, indices, study design, and statistical methods used in those studies differ. This difference has made it difficult to compare the results of this study with the results of other studies.

The present study showed that orthodontic treatment complexity does not seem to have an impact on OHRQoL. Only pretreatment psychological disability scores of the moderate group were significantly higher than those of the difficult group, which appears unreasonable from a clinical perspective. Also, the $p$ value of the ANOVA test is very close to non-significance $(p=0.048)$. The only explanation could perhaps be the larger number of females in the moderate group. As reported in previous researches, women are more uncomfortable with their dental appearance than are men $(8,26)$.

To the authors' knowledge, only one study has evaluated the impact of orthodontic treatment complexity on OHRQoL. Onyeaso et al. (21) conducted a study including 12 to 17 year-old
Nigerian adolescents without previous orthodontic treatments and used the same measurement methods (OHIP-14 and ICON). They concluded that there is no relationship between orthodontic treatment complexity and OHRQoL, which is similar to the current study. The difference was that they found the highest scores in physical pain besides psychological discomfort and psychological disability. They discussed that the highest scores of physical pain may be due to tooth decay or periodontal problems. To eliminate this confusion, individuals with periodontal problems, tooth decay, chronic medical disorders, and craniofacial anomalies were excluded from this study. In this study, the highest scores were seen in the psychological discomfort and psychological disability domains before orthodontic treatment for all participants, which is similar to the study by Chen et al. (22).

The sample of this study consisted of patients who had undergone comprehensive fixed orthodontic treatment, thus representing a specific group of patients. Most of the studies showed that orthodontic treatment has a positive impact on OHRQoL (23-25). Chen et al. (23) performed a study including Chinese patients, and they concluded that after orthodontic treatment, both the scores of domain and total OHIP-14 were better than before treatment. In this study, a statistically significant difference was reported in total OHIP-14 and domain scores between pre- and post-treatment comparisons in all groups.

The associations between facial pain and various forms of malocclusion have been reported in epidemiological studies (27, 28). Although pain is thought to be a biological response to tissue damage, according to the cognitive-behavioral model, age, education level, sociocultural, and economic factors are also influential in interpreting the pain experienced by individuals. According to previous studies, females experience chronic orofacial pain more often as well as report severe oral impacts more often than males. In this study, while comparing gender, only pretreatment physical pain scores of females were significantly higher than males (29-31). The reason that females appear to suffer more pain has been an important topic of discussion and evaluation in literature.

According to the previous studies, younger individuals with malocclusion had higher scores for handicap, social disability, psychological disability, psychological discomfort, physical disability, and total OHIP-14 $(14,32)$. In this study, the pretreatment psychological discomfort and psychological disability scores for adults were statistically higher than those of adolescents; in addition, the post-treatment psychological disability scores of adults were statistically lower than those of adolescents. It can be explained that feeling psychological discomfort of their appearance is more likely to be the main factor in seeking orthodontic treatment in adults, and they are also psychologically more benefited than adolescents after the orthodontic treatment.

The QoL is increasingly acknowledged as a valid, appropriate, and significant indicator of service need and intervention outcome in contemporary public health research and practice (33). 
The present study provides information concerning the impact of orthodontic treatment among two different age groups in both genders and demonstrates a baseline knowledge of oral health and refutes the null hypothesis. Although many researches have studied the effect of orthodontic treatment on OHRQoL, it was difficult to compare their results with the outcome of this study due to variations in the variables incorporated.

Further research is still needed to overcome the limitations of this study, which include lack of information of socio-economic status, educational level of participants, types of malocclusions in terms of classification and severity, and the relation of oral status with general health. In addition, further evolution of the concept of an orthodontic treatment index to include psychosocial criteria is still required. The ICON relates only to the functional measurement for orthodontic treatment and should be used in combination with appropriate psychological indicators such as OHIP-14.

The other limitations in this study must be taken into consideration. The use of the OHIP-14 questionnaire in adolescents is also a major limitation. The OHIP-14 is only validated for Turkish adults and not for adolescents. Although this index was administered through face-to-face interviews, and patients were able to ask questions when they did not understand something, the results should be interpreted with caution.

The usefulness of the findings from this study is limited as the sample is not necessarily representative of all members of the general population. The determination of sample size was based on the data from a previous study (16), by setting type I error at 0.05 and type II error at 0.20 (80\% power). A sample size of minimum 97 subjects would be needed to demonstrate a significant change in OHRQoL from T1 to T2. To account for possible dropouts during the study, 102 participants were included in this study. Another potential limitation was the size differences of the complexity groups, age groups and gender groups, which may cause bias and should be considered when interpreting results. A larger sample size would increase the sensitivity of the impact of malocclusion on the OHRQoL, which could be explored completely among gender and various age groups to a greater extent.

\section{CONCLUSION}

- Within the limitations of this study, it was observed that orthodontic treatment improves OHRQoL, and orthodontic treatment complexity does not seem to have an impact on OHRQoL.

- This study provides fairly strong evidence that adult subjects are more likely to report "psychological discomfort" of their appearance, which is associated with the impairment in OHRQoL. They reported positive oral health status from a psychological perspective compared to adolescents as a result of orthodontic treatment. In addition, female subjects appear to experience more physical pain than males during orthodontic treatment.
- Given the negative consequences of orthodontic treatment on OHRQoL, it is important that disease prevention measures are promoted when formulating a health policy. It is likely that there will be greater demand from patients for treatment aimed at reducing the severity of the disease.

Ethics Committee Approval: Ethics committee approval was received for this study from the Ethics Committee of İstanbul Medipol University.

Informed Consent: Written informed consent was obtained from the patients who participated in this study.

\section{Peer-review: Externally peer-reviewed.}

Acknowledgments: The authors would like to thank to Dr. Osama Al-Jabrah, Department of Prosthetic Dentistry, King Hussein Medical Center, Amman, Jordan, and Prof. Dr. Arzu Arı Demirkaya, Department of Orthodontics, İstanbul Okan University, İstanbul, Turkey for their valuable contributions.

Author Contributions: Concept - H.K.O., G.S.; Design - H.K.O., G.S.; Data Collection and/or Processing - H.K.O., G.S.; Analysis and/or Interpretation - H.K.O., G.S.; Literature Search - H.K.O., G.S.; Writing Manuscript - H.K.O., G.S.; Critical Review - H.K.O., G.S.

Conflict of Interest: The authors have no conflict of interest to declare.

Financial Disclosure: The authors declared that this study has received no financial support.

\section{REFERENCES}

1. DeGuzman L, Baniraei D, Vig KWL, Vig PS, Weyant RJ, O'Brien KD. The validation of the peer assessment rating index for malocclusion severity and treatment difficulty. Am J Orthodont Dentofac Orthoped 1995; 107: 72-6. [CrossRef]

2. Marya CM, Baiju CS, Nagpal R, Rekhi A. Oral Health Related Quality of Life and it's impact on elderly people. Ind J Dent Sci 2012; 4s: 12732 (Supplementary Issue).

3. Naito M, Yuasa H, Nomura Y, Nakayama T, Hamajima N, Hanada N. Oral health status and health-related quality of life: a systematic review. J Oral Sci 2006; 48: 1-7. [CrossRef]

4. El Osta N, Tubert-Jeannin S, Hennequin M, Naaman NBA, El Osta L, Geahchan N. Comparison of the OHIP-14 and GOHAl as measures of oral health among elderly in Lebanon. Health Qual Life Outcomes 2012; 10: 131-40. [CrossRef]

5. Slade GD. Measuring oral health and quality of life. Chapel Hill: Dental Ecology, University of North Carolina, North Carolina, USA: 1997.

6. Pommer B. Use of the Oral Health Impact Profile (OHIP) in clinical oral implant research. J Dent Oral Craniofac Epidem 2013; 1: 3-10.

7. Richmond S, Daniels CP, Fox N, Wright J. The professional perception of orthodontic treatment complexity. Br Dent J 1997; 183: 3715. [CrossRef]

8. Stephens CD, Harradine NW. Changes in the complexity of orthodontic treatment for patients referred to a teaching hospital. $\mathrm{Br}$ J Orthodont 1988; 15: 27-32. [CrossRef]

9. Rowe TK, Weintraub JA, Vig PS, Kowalski C J, Vig KWL. The influence of malocclusion components on perceived severity and treatment difficulty. J Dent Res 1990; 69: 260.

10. Hunt O, Hepper P, Johnston C, Stevenson M, Burden D. Professional perceptions of the benefits of orthodontic treatment. Eur J Orthod 2001; 23: 315-23. [CrossRef]

11. Shaw WC, Richmond S, O'Brien KD, Brook P, Stephens CD: Quality control in orthodontics: indices of treatment need and treatment standards. Br Dent J 1991; 170: 107-12. [CrossRef] 
12. Marques LS, Ramos-Jorge ML, Paiva SM, Pordeus IA. Malocclusion: esthetic impact and quality of life among Brazilian schoolchildren. Am J Orthod Dentofacial Orthop 2006; 129: 424-7. [CrossRef]

13. Shaw WC. Factors influencing the desire for orthodontic treatment. Eur J Orthod 1981; 3: 151-16. [CrossRef]

14. Ashari A, Mohamed AM. Relationship of the Dental Aesthetic Index to the oral health-related quality of life. Angle Orthod 2016; 86: 33742. [CrossRef]

15. Clijmans M, Lemiere J, Fieuws S, Willems G. Impact of self-esteem and personality traits on the association between orthodontic treatment need and oral health-related quality of life in adults seeking orthodontic treatment. Eur J Orthod 2015; 37: 643-50. [CrossRef]

16. de Couto Nascimento V, de Castro Ferreira Conti AC, de Almeida Cardoso M, Valarelli DP, de Almeida-Pedrin RR. Impact of orthodontic treatment on self-esteem and quality of life of adult patients requiring oral rehabilitation. Angle Orthod 2016; 88: 1-7. [CrossRef]

17. Mumcu G, Inanç N, Ergun T, Ikiz K, Gunes M, Islek U, et al. Oral health related quality of life is affected by disease activity in Behçet's disease. Oral Disease 2006; 12: 145-51. [CrossRef]

18. Daniels C, Richmond S. The development of the index of complexity, outcome and need (ICON). J Orthod 2000; 27: 149-62. [CrossRef]

19. Choi SH, Kim JS, Cha JY, Hwang CJ. Effect of malocclusion severity on oral health-related quality of life and food intake ability in a Korean population. Am J Orthod Dentofacial Orthop 2016; 149; 38490. [CrossRef]

20. Badran SA. The effect of malocclusion and self-perceived aesthetics on the self-esteem of a sample of Jordanian adolescents. Eur J Orthod 2010; 32: 638-44. [CrossRef]

21. Onyeaso CO. Orthodontic treatment complexity and need with associated oral health-related quality of life in Nigerian adolescents. Oral Health Prev Dent 2009; 7: 235-41.

22. Chen M, Feng ZC, Liu X, Li ZM, Cai B, Wang DW. Impact of malocclusion on oral health-related quality of life in young adults. Angle Orthod 2015; 85: 986-91. [CrossRef]
23. Chen M, Wang DW, Wu LP. Fixed orthodontic appliance therapy and its impact on oral health-related quality of life in Chinese patients. Angle Orthod 2010; 80: 49-5. [CrossRef]

24. de Oliveira CM, Sheiham A. Orthodontic treatment and its impact on oral health-related quality of life in Brazilian adolescents. J Orthod 2004; 31: 20-7. [CrossRef]

25. Feu D, Miguel JA, Celeste RK, Oliveira BH. Effect of orthodontic treatment on oral health-related quality of life. Angle Orthod 2013; 83: 892-8. [CrossRef]

26. Sheats RD, McGorray SP, Keeling SD, Wheeler TT, King GJ. Occlusal traits and perception of orthodontic need in eighth grade students. Angle Orthod 1998; 68: 107-14.

27. Sipilä K, Ensio K, Hanhela H, Zitting P, Pirttiniemi P, Raustia A. Occlusal characteristics in subjects with facial pain compared to a painfree control group. Cranio 2006; 24: 245-51. [CrossRef]

28. Schmitter M, Balke Z, Hassel A, Ohlmann B, Rammelsberg P. The prevalence of myofacial pain and its associations with occlusal factors in a threshold country non-patient population. Clin Oral Investig 2007; 11: 277-81. [CrossRef]

29. Robinson ME, Gagnon CM, Riley JL III, Price DD. Altering gender role expectations: effects on pain tolerance, pain threshold, and pain ratings. J Pain 2003; 4: 284-8. [CrossRef]

30. Fillingim RB, King CD, Ribeiro-Dasilva MC, Rahim-Williams B, Riley $J L$ 3rd. Sex, gender, and pain: a review of recent clinical and experimental findings. J Pain 2009; 10: 447-85. [CrossRef]

31. Edwards $C L$, Fillingim RB, Keefe F. Race, ethnicity and pain. J Pain 2001; 94: 133-7. [CrossRef]

32. Clijmans M, Lemiere J, Fieuws S, Willems G: Impact of self-esteem and personality traits on the association between orthodontic treatment need and oral health-related quality of life in adults seeking orthodontic treatment. Eur J Orthod 2015; 37: 643-50. [CrossRef]

33. Mack F, Schwahn C, Feine JS, Mundt T, Bernhardt O, John U, et al. The impact of tooth loss on general health related to quality of life among elderly Pomeranians: Results from the Study of Health in Pomerania (SHIP-0). Int J Prosthodont 2005; 18: 414-9. 